\title{
Development of Personal Protective Clothing for Reducing Exposure to Insecticides in Pesticide Applicators
}

\author{
Manoch Naksata ${ }^{1}$, Anucha Watcharapasorn ${ }^{1,2}$, Surat Hongsibsong ${ }^{3, *}$ (i) and \\ Ratana Sapbamrer ${ }^{4, *}$ \\ 1 Department of Physics and Material Science, Faculty of Science, Chiang Mai University, 239, \\ Huay Kaew Road, Suthep Subdistrict, Muang District, Chiang Mai 50200, Thailand; \\ manochnak@gmail.com (M.N.); anucha@stanfordalumni.org (A.W.) \\ 2 Research Center in Physics and Astronomy, Faculty of Science, Chiang Mai University, \\ Chiang Mai 50200, Thailand \\ 3 School of Health Sciences Research, Research Institute for Health Sciences, Chiang Mai University, \\ 110 Inthavaroros Road, Sriphum Subdistrict, Muang District, Chiang Mai 50200, Thailand \\ 4 Department of Community Medicine, Faculty of Medicine, Chiang Mai University, 110 Inthavaroros Road, \\ Sri Phum Subdistrict, Muang District, Chiang Mai 50200, Thailand \\ * Correspondence: s_hongsibsong@hotmail.com (S.H.); ratana.sapbamrer@cmu.ac.th (R.S.); \\ Tel.: +6653-942-508 (S.H.); +6653-935-472 (R.S.)
}

Received: 14 April 2020; Accepted: 7 May 2020; Published: 9 May 2020

\begin{abstract}
Wearing appropriate personal protective equipment during the application of pesticides is one method of reducing dermal exposure to pesticides. Thus, the aim of this research is to develop personal protective clothing (PPC) coated with gum rosin and investigate the efficiency of its level of protection against chlorpyrifos and cypermethrin. Comparison of the protection efficiency of each PPC with Tychem ${ }^{\circledR} \mathrm{C}$ coveralls was also investigated. Five commercially available cotton fabrics were chosen for tailoring the PPC, and then, the PPC was coated with a gum rosin finish to provide water repellence. The efficiency of the level of protection of the gum rosin-coated PPC against insecticides was tested in a laboratory (closed chamber). The remarkable findings were that the $\%$ protection efficiencies for all the PPC, with the exception of one, were not significantly different to those for Tychem ${ }^{\circledR}$ C coveralls. The protection efficiencies ranged from $99.85 \%$ to $99.97 \%$ against chlorpyrifos and $99.11 \%$ to $99.89 \%$ against cypermethrin. Therefore, our results suggest that gum rosin-coated clothing provided satisfactory levels of protection against insecticides and could be considered as suitable protective clothing for pesticide applicators. Choice of an appropriate fabric for coating with gum rosin also needs to be considered. A further study in field conditions is warranted to confirm the protection efficiency in a working environment.
\end{abstract}

Keywords: personal protective equipment; personal protective clothing; fabric; pesticide; insecticide; chlorpyrifos; cypermethrin; safety; risk reduction

\section{Introduction}

It has been known that pesticides are associated with acute and chronic health effects in agricultural workers who are exposed to them. Exposure to pesticides can potentially occur during mixing, loading, application of the pesticides, and other activities in farms. Due to pesticide application taking up the highest proportion of the working time in comparison to the tasks of mixing and loading, exposure during pesticide application might be more significant [1,2]. The primary route of exposure to pesticides is dermal contact, while exposure through inhalation is rather limited, due to the low vapor 
pressures of some pesticides [3-5]. Although national and international sectors have made an effort to reduce pesticide exposure in agricultural workers by laying down regulation and legislations, the implementation of engineering and system controls is difficult for many [6]. Therefore, wearing appropriate personal protective equipment in all activities associated with pesticide handling is one measure to reduce dermal exposure to the toxic chemicals involved $[6,7]$.

With regard to personal protective clothing (PPC), clothing made of non-woven synthetic materials which are coated in certain chemicals to make it non-porous has the highest levels of protection against pesticides [8-10]. A category III type 3 partial body gown (Tychem ${ }^{\circledR}$ F Gown style) had a protective effect of $98.7 \%$, while Tyvek coveralls had a protective effect higher than $97 \%$ [8,9]. However, these items of PPC are quite expensive, so consequently, most agricultural workers cannot afford them [11-13]. These items of PPC can also interfere with heat exchange, causing discomfort and development of heat stress under hot and humid conditions [14,15]. Therefore, the high price and discomfort of these PPC are the main cited reasons agricultural workers do not use them when working with pesticides [11]. A systematic review by Sapbamrer and Thammachai [16] stated that a long-sleeved shirt and long-sleeved trousers were the most basic PPE worn among pesticide handlers across the world. Most agricultural workers wore work clothing made of woven fabric when working on farms, resulting in the easy penetration of pesticides through to the skin [1,17]. Pesticide penetration through woven fabric depends on type of pesticide, fabric thickness, fabric weight, yarn twist, and fabric composition [18-21].

The outcomes of some studies have facilitated the development of woven fabrics coated with certain chemicals (including polyurethane, rubber, teflon, and fluorocarbon) to protect against pesticides and simultaneously confer better thermal comfort [22-25]. The study by Naksata and Naksata (Petty Patent no. 7450, 8 July 2010, Thailand) also reported on the efficacy of a novel cotton fabric coated with gum rosin to provide water repellence [26]. Cotton fabric has numerous pores in a woven structure and can absorb large amounts of liquid including sweat, leading to wearers feeling more comfortable in hot conditions [27]. Gum rosin is a natural resin, which is extracted from pine trees. It is usually used in its crude raw form for the production of soap, varnishes, sealing wax, and various adhesives [28]. The cotton which was coated with gum rosin showed a water resistance for longer than 24 hours and a contact angle of water repellency greater than $120^{\circ}$ [26]. We expect that the gum rosin-coated clothing can protect against pesticides and make wearers comfortable when applying pesticides. This study focuses on insecticides, which are the most extensively used pesticides in agriculture worldwide, our main focus being chlorpyrifos and cypermethrin. Thus, the aim of this research is to develop PPC which is made of cotton coated with gum rosin and investigate the efficiency of the clothing in the level of protection given against chlorpyrifos and cypermethrin. Comparison of the protection efficiency of each PPC with Tychem ${ }^{\circledR} \mathrm{C}$ coveralls was also investigated.

\section{Materials and Methods}

\subsection{Coating of Personal Protective Clothing with Gum Rosin}

Five commercially available cotton fabrics (PPC1-PPC5) were chosen for the making of the PPC. The five fabrics were selected because they gave the highest level of protection against pesticides in a preliminary laboratory investigation. Fabric construction, fabric count, weight, and thickness of each cotton fabric were measured (Figure 1). Fabric count and weight were measured in accordance with ASTM D3775 and ASTM 3776, respectively. Fabric thickness was measured in accordance with ASTM D1777-96. A Tychem ${ }^{\circledR} \mathrm{C}$ coverall (DuPont, Vietnam) was also used in the study for comparison of the level of protective efficiency with the PPC in our study. The PPC was made into coveralls of a similar size and pattern as the Tychem ${ }^{\circledR} \mathrm{C}$ coverall. The coveralls were tailored to fit the manikin used in the tests. 


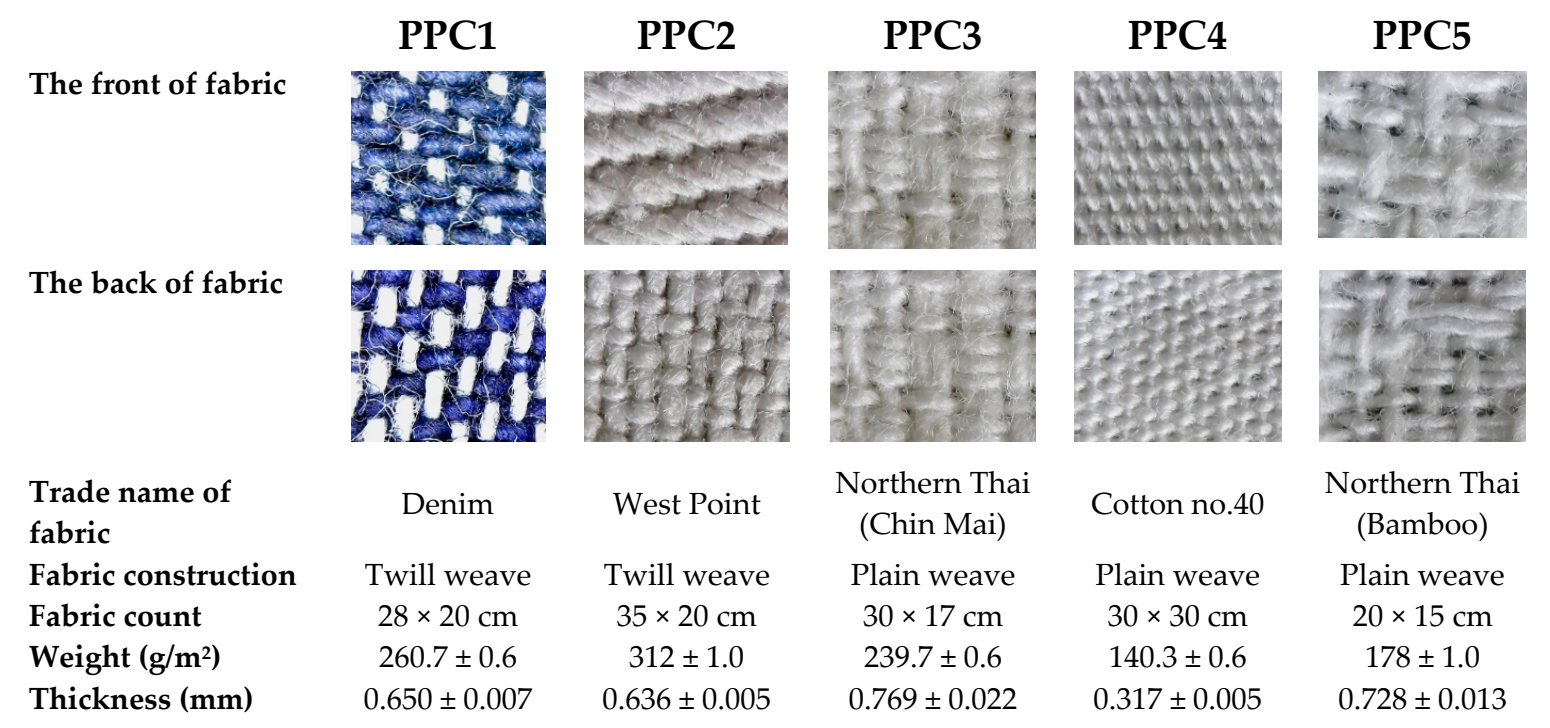

Figure 1. Properties of fabrics which were used to tailored personal protective clothing (PPC).

The PPC was coated with gum rosin finish to provide water repellence. Physical and chemical characteristics of gum rosin are as follows: pale yellow to amber fragments, molecular formula $\mathrm{C}_{20} \mathrm{H}_{30} \mathrm{O}_{2}$, molecular weight $302.5 \mathrm{~g} / \mathrm{mole}$, density $1.07 \mathrm{~g} / \mathrm{cm}^{3}$, melting point $100-150{ }^{\circ} \mathrm{C}$, and flash point $187^{\circ} \mathrm{C}$ [29]. The coating process was completed following the method described by Naksata and Naksata (Petty Patent no.7450, 8 July 2010, Thailand) [26]. Prior to the coating process, the coveralls were laundered with commercially available detergent and tap water and dried at $60-80{ }^{\circ} \mathrm{C}$. They were then soaked in gum rosin solution 1-3\% w/v (M/L = 1:20) (Chemwinfo Co., Ltd, Bangkok, Thailand) for $15 \mathrm{~min}$, and potassium aluminum sulfate $1-3 \% \mathrm{w} / \mathrm{v}(\mathrm{M} / \mathrm{L}=1: 20)$ (World Chemical Co., Ltd, Chiang Mai province, Thailand) for $15 \mathrm{~min}$. After the coating process, the coveralls were spin-dried at 3000 rounds per min for $3 \mathrm{~min}$ and dried at $60-80^{\circ} \mathrm{C}$.

\subsection{Test Insecticides}

Two insecticides, including chlorpyrifos $40 \% \mathrm{w} / \mathrm{v}$, emulsifiable concentrate (Tradename: Cosmic 40, ICP Ladda Co.,Ltd, Thailand), and cypermethrin 35\% w/v, emulsifiable concentrate (Tradename: Thaiperthroid 35, Pato Chemical Co., Ltd, Bangkok, Thailand), were used in the study. Before the experiments the insecticides were diluted to a final concentration of $2 \mathrm{~mL} / 1 \mathrm{~L}$ of water, which is the recommended dilution on the labels on the insecticides.

\subsection{Closed Chamber Testing of the Protective Efficiency of the Gum Rosin-Coated PPC}

The efficiency of the gum rosin-coated PPC in its ability to protect against insecticides was tested in a closed chamber, modified from the ASTM F1359/F1359M-16a standard (Procedure A). The size of the closed chamber and position of the nozzles are shown in Figure 2.

Five nozzles were positioned in the same vertical plane, one at the top center above the clothed manikin, two nozzles at the upper sides, and two nozzles at the lower sides. The pressure for spraying the insecticides was set at $3 \pm 0.2 \mathrm{~L} / \mathrm{min}$, spraying taking place simultaneously through all nozzles. The spraying time was set at $5 \mathrm{~min}$ in each quadrant from $0^{\circ}$ to $360^{\circ}$, resulting in $20 \mathrm{~min}$ of total spraying time. The height of the manikin used was $183 \mathrm{~cm}$, and it was positioned at the center of the chamber. Before testing, the opening of the hooded garment was sealed with waterproof tape. 


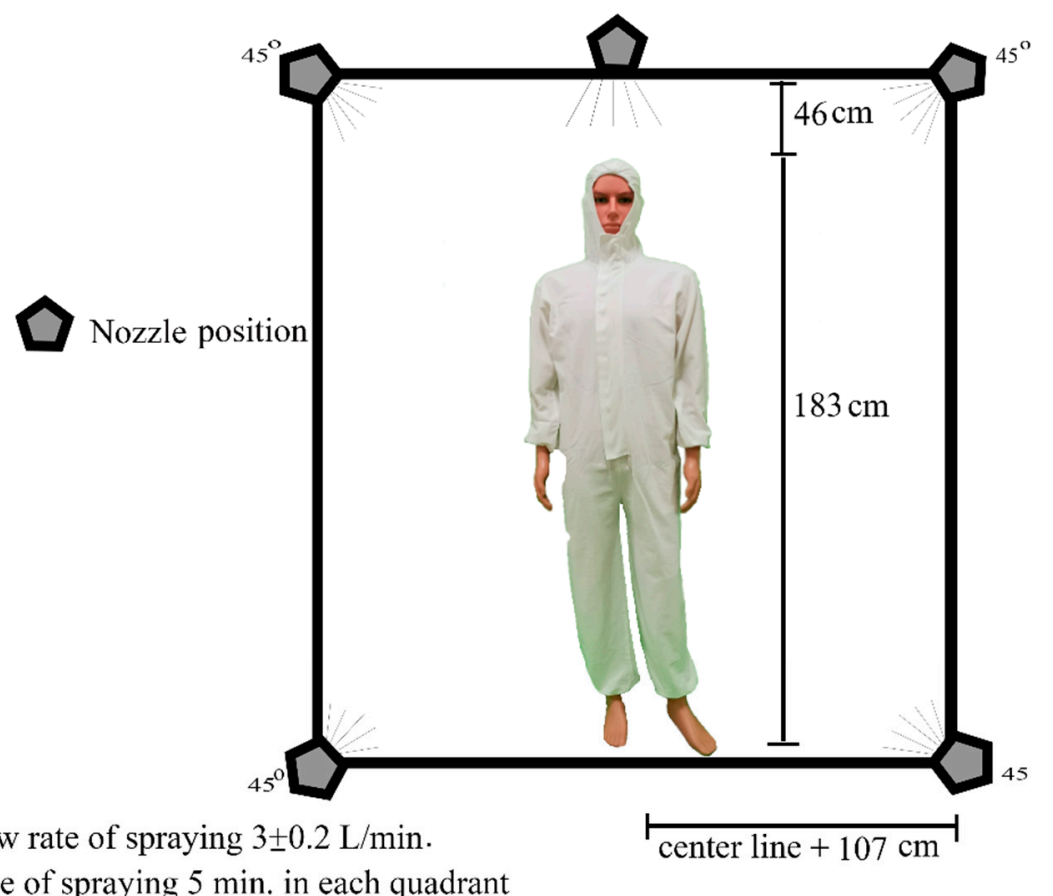

Time of spraying $5 \mathrm{~min}$. in each quadrant

Total spraying time $20 \mathrm{~min}$.

Figure 2. Closed chamber for experiment.

\subsection{Measurement of Protection Efficiency of the Gum Rosin-Coated PPC}

Dermal exposure was measured using a pads technique. Potential dermal exposure (PDE) and actual dermal exposure (ADE) were measured. PDE is representative of the amount of insecticide that comes into contact with the body surface when the manikin is protected with PPC. ADE represents the total amount of insecticides that comes into contact with uncovered skin.

Before the manikin was dressed in the coverall, $10 \mathrm{~cm}$ diameter pads of alpha cellulose backed with aluminum foil were attached to various locations of the manikin body for measuring PDE. The locations were as follows: head, neck, chest, back, upper arm, forearm, belly, genital area, upper leg, and lower leg [30]. External pads were also attached to the coverall at the same position as the internal pads for measuring ADE. At the end of the experiment, the pads were removed and analyzed to assess the concentration of the insecticide. The procedure was repeated 6 times for each piece of potential PPC. All pad samples were kept at $-20^{\circ} \mathrm{C}$ until chemical analysis.

\subsection{Analysis of Insecticides}

Chlorpyrifos (CAS Number: 2921-88-2) and Cypermethrin (CAS Number: 52315-07-8) were purchased from Dr. Ehrenstorfer GmbH (Augsburg, Germany). The alpha cellulose filter samples were extracted and analyzed using a modification of the method described by Sapbamrer and Hongsibsong [31] and Pakvilai et al. [32]. Twenty mL of acetonitrile (HPLC grade, J.T.Baker, Phillipsburg, NJ, USA) was used for paper extraction. This was shaken for $5 \mathrm{~min}$ in a $50-\mathrm{mL}$ centrifuge tube. The alpha cellulose filter was repeated extract 2 times with $20 \mathrm{~mL}$ and $10 \mathrm{~mL}$ of acetonitrile. The extracted solutions were pooled and $3 \mathrm{~g}$ of sodium chloride (analytical grade, Fluka, Buchs, Germany) and magnesium sulfate (analytical grade, Fluka, Buchs, Germany) were added to remove the water. The combined solution was filtered through filter paper containing $2 \mathrm{~g}$ of anhydrous sodium sulfate (analytical grade, Fluka, Buchs, Germany) into $100 \mathrm{~mL}$ evaporating flask and evaporated to dryness using a rotary evaporator in a water bath at $40^{\circ} \mathrm{C}$. The flask was rinsed with $5 \mathrm{ml}$ ethyl acetate (HPLC grade, J.T.Baker, Phillipsburg, NJ, USA), transferred to a $15 \mathrm{~mL}$ glass tube, and dried with nitrogen. Finally, the residues 
were extracted using a $0.25 \mu \mathrm{m}$ syringe filter and reconstituted in $1 \mathrm{~mL}$ of ethyl acetate for analysis by gas chromatography (GC).

The chlorpyrifos samples were analyzed using GC (Hewlett-Packard 7890 Series, Palo Alto, CA, USA). The apparatus was equipped with a flame photometric detector, a capillary column (DB-1701, 14\% cyanopropyl-phenyl-methylpolysiloxane column $-0.25 \mathrm{~mm}$ I.D. $\times 30 \mathrm{~m}$ length $\times$ $0.25 \mu \mathrm{m}$ film thickness). Temperature was $250{ }^{\circ} \mathrm{C}$ for the injection port (spitless mode) and $250{ }^{\circ} \mathrm{C}$ for the detector port. The cypermethrin samples were also analyzed using GC (Hewlett-Packard 7890 Series), but the apparatus was equipped with an electron capture detector, a capillary column (HP-5, 5\%-phenyl-methylpolysiloxane nonpolar column $-0.25 \mathrm{~mm}$ I.D. $\times 30 \mathrm{~m}$ length $\times 0.25 \mu \mathrm{m}$ film thickness). Temperature was $250{ }^{\circ} \mathrm{C}$ for the injection port (spitless mode) and $300{ }^{\circ} \mathrm{C}$ for the detector port. Temperature programming of the oven was as follows: initial temperature $100{ }^{\circ} \mathrm{C}$ for $1 \mathrm{~min}$, first ramp at $5{ }^{\circ} \mathrm{C} / \mathrm{min}$ to $180{ }^{\circ} \mathrm{C}(2 \mathrm{~min})$, second ramp at $2{ }^{\circ} \mathrm{C} / \mathrm{min}$ to $200{ }^{\circ} \mathrm{C}(1 \mathrm{~min})$, third ramp at $5{ }^{\circ} \mathrm{C} / \mathrm{min}$ to $280^{\circ} \mathrm{C}(4 \mathrm{~min})$, and final temperature maintained at $300^{\circ} \mathrm{C}$ for $4 \mathrm{~min}$. The carrier gas was helium $99.999 \%$ at $1.5 \mathrm{~mL} / \mathrm{min}$, constant flow mode. The total run time was $50 \mathrm{~min}$.

\subsection{Quality Control}

The results of the quality control procedures are presented in Table 1. Limit of detection (LOD) and limit of quantification (LOQ) for chlorpyrifos were $0.020 \mu \mathrm{g}$ and $0.025 \mu \mathrm{g}$, respectively. The LOD and LOQ for cypermethrin were $0.012 \mu \mathrm{g}$ and $0.025 \mu \mathrm{g}$, respectively. Relative SD coefficient (\% RSD) of chlorpyrifos was $5.7 \%$ for intra-batch and 3.0\% for inter-batch, while the $\%$ RSD of cypermethrin was $6.1 \%$ for intra-batch and $7.6 \%$ for inter-batch. Recoveries ranged from 85.5 to $126.5 \%$ for chlorpyrifos, and 93.9 to $102.1 \%$ for cypermethrin.

Table 1. Quality control for insecticide analysis.

\begin{tabular}{ccccccccc}
\hline \multirow{2}{*}{ Pesticide } & LOD & LOQ & Correlation & \multicolumn{3}{c}{ Recovery \% } & \multicolumn{2}{c}{ Precision, \% RSD } \\
\cline { 5 - 9 } & $(\boldsymbol{\mu g})$ & $(\mu \mathrm{g})$ & $\left(\boldsymbol{r}^{\mathbf{2}}\right)$ & Low & Medium & High & $\begin{array}{c}\text { Intra-Bath } \\
(\boldsymbol{n}=\mathbf{1 0})\end{array}$ & $\begin{array}{c}\text { Inter-Bath } \\
(\boldsymbol{n}=\mathbf{5})\end{array}$ \\
\hline Chlorpyrifos & 0.020 & 0.025 & 0.99890 & 98.1 & 85.5 & 126.5 & 5.7 & 3.0 \\
Cypermethrin & 0.012 & 0.025 & 0.99945 & 93.9 & 102.1 & 98.2 & 6.1 & 7.6 \\
\hline
\end{tabular}

\subsection{Data Analysis}

Surface area of each pad was $95.071 \mathrm{~cm}^{2}$, and ten pads were attached to various locations of the manikin body; therefore, total surface area of total pads was $950.71 \mathrm{~cm}^{2}$. Total surface area of the manikin body (except face, hands, and feet) was 19,130 $\mathrm{cm}^{2}$. Therefore, PDA and ADE for the total surface body of manikin were calculated by multiplying the amounts of insecticides in total pads by 20.12. The percentage of protection efficiency (\% efficiency) to insecticides are as follows:

$$
\% \text { efficiency }=((\mathrm{ADE}-\mathrm{PDE}) \times 100) / \mathrm{ADE}
$$

where

$\mathrm{ADE}=$ total amounts of insecticides from external pads

$\mathrm{PDE}=$ total amounts of insecticides from internal pads

Descriptive statistics, including mean and standard deviation (SD) were used. A one-way ANOVA (Tamhane's T2 test) was used for testing the comparison of the protection efficiency to insecticides between the gum rosin-coated PPC and Tychem ${ }^{\circledR} \mathrm{C}$ coveralls. 


\section{Results}

3.1. Actual Dermal Exposure (ADE) and Potential Dermal Exposure (PDE) for the Total Surface Body of Manikin

ADE and PDE (ug) for the total surface body of manikin are presented in Table 2. ADE for chlorpyrifos and cypermethrin were 41,982.38 $\pm 6734.00 \mu \mathrm{g}$ and 52,580.36 $\pm 7502.34 \mu \mathrm{g}$, respectively. PDE for chlorpyrifos ranged from $14.15 \pm 7.67 \mu \mathrm{g}$ for PPC1 to $6660.36 \pm 6070.98 \mu \mathrm{g}$ for PPC5. PDE for cypermethrin ranged from $56.01 \pm 55.88 \mu \mathrm{g}$ for PPC1 to 85,026.91 \pm 29,890.51 $\mu \mathrm{g}$ for PPC5.

Table 2. Actual dermal exposure (ADE) and potential dermal exposure (PDE) for the total surface body of manikin.

\begin{tabular}{cccccc}
\hline \multirow{2}{*}{ ADE/PDE } & \multicolumn{2}{c}{ Chlorpyrifos $(\mu \mathrm{g})$} & \multicolumn{2}{c}{ Cypermethrin $(\mu \mathrm{g})$} \\
\cline { 3 - 6 } & & Mean \pm SD. & Median & Mean \pm SD. & Median \\
\hline ADE & $(n=6)$ & $41,982.38 \pm 6734.00$ & $41,828.42$ & $52,580.36 \pm 7502.34$ & $54,711.38$ \\
\hline PDE & PPC1 $(n=6)$ & $14.15 \pm 7.67$ & 11.71 & $56.01 \pm 55.88$ & 37.47 \\
& PPC2 $(n=6)$ & $25.41 \pm 16.58$ & 24.99 & $148.13 \pm 111.58$ & 134.29 \\
& PPC3 $(n=6)$ & $29.76 \pm 49.35$ & 8.91 & $222.68 \pm 290.48$ & 160.88 \\
& PPC4 $(n=6)$ & $61.80 \pm 98.31$ & 27.83 & $468.16 \pm 744.30$ & 219.45 \\
& PPC5 $(n=6)$ & $6660.36 \pm 6070.98$ & 6642.88 & $85,026.91 \pm 29,890.51$ & $75,157.34$ \\
& Tychem ${ }^{\circledR}$ C & $21.36 \pm 8.92$ & 21.35 & nd & nd \\
& coveralls $(n=6)$ & & & & \\
\hline
\end{tabular}

nd $=$ not detected.

\subsection{Protection Efficiency of the Gum Rosin-Coated PPC}

Percentage of protection efficiency of each PPC are presented in Table 3. The results found that $\%$ protection efficiency for chlorpyrifos was $99.97 \pm 0.02 \%$ for PPC1, $99.94 \pm 0.04 \%$ for PPC $2,99.93 \pm 0.12 \%$ for PPC $3,99.85 \pm 0.23 \%$ for PPC4, and $84.14 \pm 14.46 \%$ for PPC5. The proportion of protection efficiency for cypermethrin was $99.89 \pm 0.11 \%$ for PPC1, $99.72 \pm 0.21 \%$ for PPC $2,99.58 \pm 0.55 \%$ for PPC $3,99.11 \pm 1.42 \%$ for PPC4, and $-61.71 \pm 56.85 \%$ for PPC 5 . When we compared the protection efficiency of each PPC with Tychem ${ }^{\circledR}$ C coveralls, the \% protection efficiency for all PPC, except PPC5, was not significantly different to those for Tychem ${ }^{\circledR} \mathrm{C}$ coveralls. Interestingly, the highest level of protection efficiency was found in PPC1, followed by PPC2.

Table 3. Percentage of protection efficiency for chlorpyrifos and cypermethrin.

\begin{tabular}{|c|c|c|c|c|c|c|}
\hline \multirow{2}{*}{ Types of Clothing } & \multicolumn{3}{|c|}{ Chlorpyrifos } & \multicolumn{3}{|c|}{ Cypermethrin } \\
\hline & Mean \pm SD & Median & $p$-Value & Mean \pm SD & Median & $p$-Value \\
\hline $\operatorname{PPC} 1(n=6)^{\mathrm{a}}$ & $99.97 \pm 0.02$ & 99.97 & & $99.89 \pm 0.11$ & 99.93 & \\
\hline PPC2 $(n=6)^{\mathrm{b}}$ & $99.94 \pm 0.04$ & 99.94 & & $99.72 \pm 0.21$ & 99.74 & \\
\hline $\operatorname{PPC} 3(n=6)^{\mathrm{c}}$ & $99.93 \pm 0.12$ & 99.98 & $<0.001$ & $99.58 \pm 0.55$ & 99.69 & $<0.001$ \\
\hline PPC4 $(n=6)^{\mathrm{d}}$ & $99.85 \pm 0.23$ & 99.93 & ae,be,ce,de,ef & $99.11 \pm 1.42$ & 99.58 & ae,be,ce,de,ef \\
\hline $\operatorname{PPC5}(n=6)^{\mathrm{e}}$ & $84.14 \pm 14.46$ & 84.18 & & $-61.71 \pm 56.85$ & -42.94 & \\
\hline $\begin{array}{c}\text { Tychem }{ }^{\circledR} \mathrm{C} \\
\text { coveralls }(n=6)^{\mathrm{f}}\end{array}$ & $99.95 \pm 0.02$ & 99.95 & & $100 \pm 0$ & 100 & \\
\hline
\end{tabular}

\section{Discussion}

Our results found that the \% protection efficiency for all PPC, except PPC5, was not significantly different to those for Tychem ${ }^{\circledR} \mathrm{C}$ coveralls. Interestingly, the highest level of protection efficiency was found in PPC1, followed by PPC2. These two fabrics were of twill weave construction and had the heaviest weight compared with other fabrics. It is likely that fabric construction and fabric weight were major factors affecting pesticide penetration through the garments. Our results are in agreement with 
a study by Shaw and Schiffelbein [19], which found that fabric weight and repellent finish were the significant factors affecting pesticide penetration. Previous studies also stated that other characteristics of fabrics such as thickness, yarn twist factor, cover factor, critical surface tension, and solid volume fraction, were significant parameters $[18,21]$. The PPC5 in our study had the lowest efficiency in protecting against chlorpyrifos and failed to protect against cypermethrin. This might be due to the low fabric count of the fabric and also its greater porosity when compared with other PPC (as shown in Figure 1). Therefore, our results suggest that choosing an appropriate fabric for coating with gum rosin is an important factor in the ability of a garment to protect against insecticides.

When comparing the protection efficiency among gum rosin-coated clothing and uncoated cotton clothing recorded in other studies, the efficiency of all PPC in our study, except PPC5, was higher than those of cotton fabrics from other studies. In a field study by Li et al. [33], total dermal exposure through cotton coveralls during the spraying of chlorpyrifos was investigated, and it was found that a single layer of cotton coveralls had effectiveness higher than 93\%. A study by Gao et al. [34] also investigated operator exposure during spraying chlorpyrifos in maize fields, and they found that the protective efficiency of single layer clothes made of $>70 \%$ cotton ranged from $16.9 \%$ to $68.1 \%$, depending on the experience of the sprayers and the height of maize. Regarding previous studies in other chemicals, Protano et al. [9] estimated the performance of cotton garments for protecting against pesticides (including azinphos-methyl, terbutylazine, alachlor, dimethoate, and dicamba) during open field treatment. They reported that the protection efficiency conferred by cotton garments ranged from $84.1 \%$ to $92.5 \%$. A laboratory study also found the protection efficiency of cotton fabrics against chemical agents ranged from $57.5 \%$ to $89.5 \%$ [23].

When comparing the protection efficiency with other water-repellent PPC and commercial PPC, the efficiency of all PPC in our study, except PPC5, had higher levels than those of the other PPC. A study by Protano et al. [9] mentioned that protection efficiency of pesticides given by the Tyvek coveralls range was approximately $97 \%$. Similarly, Vitali et al. [35] investigated the same pesticides and claimed that the protection efficiency of specific protective garments, which were made of a synthetic material, was higher than $97.6 \%$. A study by Thouvenin et al. [8] also investigated the protection efficiency against spinosad insecticides of different clothing during mixing/loading, application, and cleaning the equipment. The results showed that the protection efficiency was $95 \%$ for water-repellent finish polyester/cotton (65/35) coveralls and $98.7 \%$ for a CategoryIII Type3 partial body gown (Tychem ${ }^{\circledR} \mathrm{F}$ Gown style). However, these three studies were conducted in field situations which could result in under-estimation of the protective effects. In field situations, other factors might affect the outcome such as experience of sprayers, body movement of the workers, types of sprayer equipment, direction of spraying, plant characteristics, and environmental conditions [32,33,36,37].

With regard to previous studies in laboratory and field conditions, Espanhol-Soares et al. [24] investigated the efficiency of fluorocarbon finished fabrics in protecting against chemicals in both laboratory and field studies (copper hydroxide in laboratory conditions and sulfate manganese in field conditions). Beige fabrics (made with 100\% cotton) and camouflaged fabrics (made with $69 \%$ cotton and $31 \%$ polyester) were coated with fluorocarbons to provide water repellence. The protection efficiency of the beige fabrics coated with fluorocarbon was approximately $96.8 \%$ for laboratory conditions and $95.8 \%$ for field studies. The efficiency of the camouflaged fabrics coated with fluorocarbon was approximately $93.9 \%$ in the laboratory and $97.1 \%$ in the field. The protection efficiency of this study was lower than that found in our study. This may be due to differences in the types of fabrics, test chemicals and experimental conditions. In addition, a study by Rahman Bhuiyan [23] also claimed that a polyurethane-aerogel incorporated coating on cotton fabrics had a protection efficiency of $100 \%$ for various chemicals. In vivo tests also evaluated the protective performance of different materials against carbamate insecticides. These included PU-coated nylon, water-oil repellent non-woven fabric based Sontara ${ }^{\circledR}$, and Gore-Tex ${ }^{\circledR}$ with Poly Tetra Fluoro Ethylene (PTFE). No pesticides residues were detected through the three fabrics, meaning that the protection efficiency of these fabrics was 100\% [10]. The protection efficiency in our study is comparable to those reported by other studies in laboratory 
conditions. Therefore, it is reasonable to suggest that gum rosin-coated clothing provides satisfactory levels of insecticide protection, and it can be considered as suitable clothing for the protection against insecticides for pesticides applicators.

A major outcome of this study is that the gum rosin-coated clothing was found to be an effective form of alternative clothing for agricultural workers to protect against insecticides because of its water-repellent characteristics, simple coating process, low cost, and raw material availability. Therefore, the gum rosin-coated clothing is suitable for agricultural workers who have limited or no purchasing power to access commercial PPC. They can use their own clothing of an appropriate material for coating with gum rosin. Furthermore, the coating process is simple, and agricultural workers could carry it out themselves in the future. However, allergic contact dermatitis from rosin contained in epilating product has been reported [38]. Therefore, the effects of the gum rosin-coated clothing and coating handlings on allergic contact dermatitis should be investigatedin further study. To add weight to the findings of this study, measurement of air permeability and other characterization of fabrics need to be carried out. Since this study investigated only first time use of the coated PPC, further tests involving multiple washes should be carried out [39]. Finally, a field study should also be carried out to explore the impact of other co-factors, such as body movement of agricultural workers and environmental conditions.

\section{Conclusions}

Gum rosin-coated clothing can be considered as suitable PPE to protect against insecticides in the case of pesticide applicators due to its water-repellent characteristics, simple coating process, low cost, and raw material availability. Choice of an appropriate fabric for coating with gum rosin was an important factor in the level of protection against insecticides. Due to its simple nature, sharing the availability of the knowledge of this process with pesticide applicators is feasible and achievable, leading to self-sufficiency in agricultural workers.

\section{Patents}

Coating process of fabrics with gum rosin followed the method described by Naksata M. and Naksata V. (Petty Patent no. 7450, 8 July 2010, Thailand, NSTDA, 2016). Naksata M. is a first author in this study.

Author Contributions: Conceptualization, R.S., M.N., and A.W.; methodology, R.S. and S.H.; validation, M.N. and S.H.; formal analysis, R.S.; investigation, R.S.; M.N. and S.H.; resources, M.N. and S.H.; data curation, R.S.; writing—original draft preparation, R.S.; writing—review and editing, R.S.; supervision, R.S.; project administration, R.S.; funding acquisition, R.S. All authors have read and agreed to the published version of the manuscript.

Funding: This study was supported by the Thailand Science Research and Innovation Fund, Thailand (Grant No. RSA6280030), the Faculty of Medicine Research Fund, Chiang Mai University Fund, Thailand (Grant No. MT 02/2562), and the Chiang Mai University Research Fund, Thailand.

Acknowledgments: We offer our thanks to the Thailand Science Research and Innovation Fund, Thailand (Grant No. RSA6280030), the Faculty of Medicine Research Fund (Grant No. MT 02/62), Chiang Mai University, Thailand (Grant No. MT02/2562), and the Chiang Mai University Research Fund, Thailand, for the funding. We offer our thanks to partial supports from the Research Center in Physics and Astronomy, Faculty of Science, Chiang Mai University. We also offer our thanks to the Research Administration Section, Faculty of Medicine, Chiang Mai University for their assistance with the editing of the English language.

Conflicts of Interest: The authors declare no conflict of interest.

\section{References}

1. Damalas, C.A.; Koutroubas, S.D. Farmers' Exposure to Pesticides: Toxicity Types and Ways of Prevention. Toxics 2016, 4, 1. [CrossRef] [PubMed]

2. Damalas, C.A.; Eleftherohorinos, I.G. Pesticide Exposure, Safety Issues, and Risk Assessment Indicators. Int. J. Environ. Res. Public Health 2011, 8, 1402-1419. [CrossRef] [PubMed] 
3. Fenske, R.A.; Farahat, F.M.; Galvin, K.; Fenske, E.K.; Olson, J.R. Contributions of inhalation and dermal exposure to chlorpyrifos dose in Egyptian cotton field workers. Int. J. Occup. Environ. Health 2012, 18, 198-209. [CrossRef] [PubMed]

4. Burns, C.; Mahlburg, W.; Dutra, J.P.J. Pesticide exposure among farm workers. Environ. Res. 2007, 105, 285-288. [CrossRef]

5. Baldi, I.; Lebailly, P.; Jean, S.; Rougetet, L.; Dulaurent, S.; Marquet, P. Pesticide contamination of workers in vineyards in France. J. Expo. Sci. Environ. Epidemiol. 2006, 16, 115-124. [CrossRef]

6. Macfarlane, E.; Carey, R.; Keegel, T.; El-Zaemay, S.; Fritschi, L. Dermal exposure associated with occupational end use of pesticides and the role of protective measures. Saf. Health Work 2013, 4, 136-141. [CrossRef]

7. Yarpuz-Bozdogan, N. The importance of personal protective equipment in pesticide applications in agriculture. Curr. Opin. Environ. Sci. Health 2018, 4, 1-4. [CrossRef]

8. Thouvenin, I.; Bouneb, F.; Mercier, T. Operator dermal exposure and protection provided by personal protective equipment and working coveralls during mixing/loading, application and sprayer cleaning in vineyards. Int. J. Occup. Saf. Ergon. 2017, 23, 229-239. [CrossRef]

9. Protano, C.; Guidotti, M.; Vitali, M. Performance of different work clothing types for reducing skin exposure to pesticides during open field treatment. Bull. Environ. Contam. Toxicol. 2009, 83, 115-119. [CrossRef]

10. Kim, R.; Kwon, Y.; Lee, H.; Limb, J. Safety evaluation of pesticide-proof materials for agricultural clothing using in-vivo test. 6th International Conference on Applied Human Factors and Ergonomics (AHFE 2015) and the Affiliated Conferences, AHFE 2015. Procedia Manuf. 2015, 3, 1888-1895. [CrossRef]

11. Garrigou, A.; Laurent, C.; Berthet, A.; Colosio, C.; Jas, N.; Daubas-Letourneux, V.; Jackson Filho, J.M.; Jouzel, J.N.; Samuel, O.; Baldi, I.; et al. Critical review of the role of PPE in the prevention of risks related to agricultural pesticide use. Saf. Sci. 2020, 123, 104527. [CrossRef]

12. Jallow, M.F.; Awadh, D.G.; Albaho, M.S.; Devi, V.Y.; Thomas, B.M. Pesticide knowledge and safety practices among farm workers in Kuwait: Results of a survey. Int. J. Environ. Res. Public Health 2017, 14, 340. [CrossRef] [PubMed]

13. Andrade-Rivas, F.; Rother, H.A. Chemical exposure reduction: Factors impacting on South African herbicide sprayers' personal protective equipment compliance and high risk work practices. Environ. Res. 2015, 142, 34-45. [CrossRef] [PubMed]

14. Watson, C.; Troynikov, O.; Lingard, H. Design considerations for low-level risk personal protective clothing: A review. Ind. Health 2019, 7, 306-325. [CrossRef] [PubMed]

15. Varghese, B.M.; Hansen, A.L.; Williams, S.; Bi, P.; Pisaniello, D.L. Heat-related injuries in Australian workplaces: Perspectives from health and safety representatives. Saf. Sci. 2020, 126, 104651. [CrossRef]

16. Sapbamrer, R.; Thammachai, A. Factors affecting use of personal protective equipment and pesticide safety practices: A systematic review. Environ. Res. 2020, 185, 109444. [CrossRef]

17. Sapbamrer, R. Pesticide use, poisoning, and knowledge and unsafe occupational practices in Thailand. New Solut. 2018, 28, 283-302. [CrossRef]

18. Zhang, X.; Raheel, M. Statistical model for predicting pesticide penetration in woven fabrics used for chemical protective clothing. Bull. Environ. Contam. Toxicol. 2003, 70, 652-659. [CrossRef]

19. Shaw, A.; Schiffelbein, P. Protective clothing for pesticide operators: Part I-selection of a reference test chemical for penetration testing. Int. J. Occup. Saf. Ergon. 2016, 22, 1-6. [CrossRef]

20. Shaw, A.; Schiffelbein, P. Protective clothing for pesticide operators: Part II-data analysis of fabric characteristics. Int. J. Occup. Saf. Ergon. 2016, 22, 7-11. [CrossRef]

21. Lee, S.; Obendorf, S.K. Statistical model of pesticide penetration through woven work clothing fabrics. Arch. Environ. Contam. Toxicol. 2005, 49, 266-273. [CrossRef] [PubMed]

22. Das, D.; Pandit, P.; Maiti, S.; Dalapati, K.K. Development of protective clothing for pesticide operation. Int. Res. J. Eng. Technol. 2016, 3, 851-855.

23. Rahman Bhuiyan, M. Polyurethane-aerogel incorporated coating on cotton fabric for chemical protection. Prog. Org. Coat. 2019, 131, 100-110. [CrossRef]

24. Espanhol-Soares, M.; Nociti, L.A.; Machado-Neto, J.G. Procedures to evaluate the efficiency of protective clothing worn by operators applying pesticide. Ann. Occup. Hyg. 2013, 57, 1041-1053. [PubMed]

25. Oliveira, M.L.; Machado-Neto, J.G. Permeability of two types of cotton fabric used in personal protective clothing to the insecticide methamidophos. Bull. Environ. Contam. Toxicol. 2005, 75, 1156-1162. [CrossRef] [PubMed] 
26. National Science and Technology Development Agency (NSTDA), Thailand. 2016. Available online: https://www.thailandtechshow.com/view_techno.php?id=34 (accessed on 12 May 2019).

27. Deng, B.; Cai, R.; Yu, Y.; Jiang, H.; Wang, C.; Li, J.; Li, L.; Yu, M.; Li, J.; Xie, L.; et al. Laundering durability of superhydrophobic cotton fabric. Adv. Mater. 2010, 22, 5473-5477. [CrossRef]

28. Palkin, S.; Smith, W.C. A new non-crystallizing gum rosin. Oil Soap. 1938, 15, 120-122. [CrossRef]

29. National Library of Medicine, National Center for Biotechnology Information. PubChem. Available online: https://pubchem.ncbi.nlm.nih.gov/compound/Gum-rosin (accessed on 5 May 2020).

30. The Organisation for Economic Co-operation and Development (OECD). Guidance Document for the Conduct of Studies of Occupational Exposure to Pesticides during Agricultural Application. Available online: https://www.oecd-ilibrary.org/environment/guidance-document-for-the-conduct-of-studies-ofoccupational-exposure-to-pesticides-during-agricultural-application_9789264078079-en (accessed on 15 January 2019).

31. Sapbamrer, R.; Hongsibsong, S. Organophosphorus pesticide residues in vegetables from farms, markets, and a supermarket around Kwan Phayao Lake of Northern Thailand. Arch. Environ. Contam. Toxicol. 2014, 67, 60-67. [CrossRef]

32. Pakvilai, N.; Prapamontol, T.; Thavornyutikarn, P.; Hongsibsong, S.; Santasup, C. A simple and sensitive GC-ECD method for detecting synthetic pyrethroid insecticide residues in vegetable and fruit samples. $C M U$ J. Sci. 2015, 42, 197-208.

33. Li, Z.; Liu, W.; Wu, C.; She, D. Effect of spraying direction on the exposure to handlers with hand-pumped knapsack sprayer in maize field. Ecotoxicol. Environ. Saf. 2019, 170, 107-111. [CrossRef]

34. Gao, B.; Tao, C.; Ye, J.; Ning, J.; Mei, X.; Jiang, Z.; Chen, S.; She, D. Measurement of operator exposure to chlorpyrifos. Pest. Manag. Sci. 2014, 70, 636-641. [CrossRef] [PubMed]

35. Vitali, M.; Protano, C.; Del Monte, A.; Ensabella, F.; Guidotti, M. Operative modalities and exposure to pesticides during open field treatments among a group of agricultural subcontractors. Arch. Environ. Contam. Toxicol. 2009, 57, 193-202. [CrossRef] [PubMed]

36. Coffman, C.W.; Obendorf, S.K.; Derksen, R.C. Pesticide deposition on coveralls during vineyard applications. Arch. Environ. Contam. Toxicol. 1999, 37, 273-279. [CrossRef] [PubMed]

37. Rincón, V.J.; Páez, F.C.; Sánchez-Hermosilla, J. Potential dermal exposure to operators applying pesticide on greenhouse crops using low-cost equipment. Sci. Total Environ. 2018, 630, 1181-1187. [CrossRef]

38. Quain, R.D.; Militello, G.; Crawford, G.H. Allergic contact dermatitis caused by colophony in an epilating product. Dermatitis 2007, 18, 96-98. [CrossRef] [PubMed]

39. Espanhol-Soares, M.; Teodoro de Oliveira, M.; Machado-Neto, J.G. Loss of effectiveness of protective clothing after its use in pesticide sprays and its multiple washes. J. Occup. Environ. Hyg. 2017, 14, 113-123. [CrossRef] [PubMed]

(C) 2020 by the authors. Licensee MDPI, Basel, Switzerland. This article is an open access article distributed under the terms and conditions of the Creative Commons Attribution (CC BY) license (http://creativecommons.org/licenses/by/4.0/). 